\title{
Interactive comment on "Science, Poetry, and Music for Landscapes of the Marche Region, Italy. Teaching the Conservation of Natural Heritage" by Olivia Nesci and Laura Valentini
}

\section{Olivia Nesci and Laura Valentini}

laura.valentini@uniurb.it

Received and published: 20 July 2020

We thank the team of reviewers who gave us good advice on the title and the abstract. We have considered their comments even if the latest version of the text has already been modified according to the suggestions of the four reviewers chosen by the editor and editor herself.

Title: the concept of heritage conservation was explained in the abstract. The term teaching is not strictly related to "school methods" but rather "to teach" ordinary people to appreciate geographic sites in a new way. 
Abstract: we answered the question: (1) how this "new approach" was developed and evaluated and (2) Why poetry and ancient music were chosen and how they have been evaluated? (3) Did this "new approach" actually have the impact that you intended in the beginning?

(1) Our approach is based on the awareness that the arts can help synthesize and convey complex scientific information and create a celebratory and positive atmosphere. Evidence suggests that the arts can deeply engage people by focusing on the emotions rather than on the comprehension, which is often emphasized in science education;

(2) We believe that the choice of poetry and music as arts is motivated by contingent needs, in fact all the arts (visual: painting, architecture and literary: narrative and so on) could be similarly used. The partnership that gave birth to this new approach is made up of people who practice music and poetry;

(3) The social impact that this new approach expected at the beginning of this research has been remarkable and confirm its effectiveness. The high participation and sharing in social networks and the attendance by a very large and varied audience, mostly without a scientific background at our live shows, demonstrated a great interest in the problems proposed.

Interactive comment on Geosci. Commun. Discuss., https://doi.org/10.5194/gc-2020-5, 2020. 